\title{
Study on Prevalence of Major Ixodid Ticks of Cattle, in Selected Sites of Harari Region, Eastern Ethiopia
}

\author{
Meseret Mohammed*, Tilaye Demissie*, Akinaw Wagari* \\ College of Veterinary Medicine and Agriculture, Addis Ababa University, Addis Ababa, Ethiopia \\ Email address: \\ meseretmohammed@gmail.com (M. Mohammed), tilayedemissie2002@gmail.com (T. Demissie), akinaw.wagari@yahoo.com (A. Wagari) \\ ${ }^{*}$ Corresponding author
}

To cite this article:

Meseret Mohammed, Tilaye Demissie, Akinaw Wagari. Study on Prevalence of Major Ixodid Ticks of Cattle, in Selected Sites of Harari Region, Eastern Ethiopia. Ecology and Evolutionary Biology. Vol. 2, No. 6, 2017, pp. 96-100. doi: 10.11648/j.eeb.20170206.11

Received: August 2, 2017; Accepted: October 19, 2017; Published: December 7, 2017

\begin{abstract}
A cross sectional study was conducted on the identification and prevalence estimation of cattle tick species in selected areas of Harari Regional State from December 2015 to April 2016 with a total number of 384 cattle. Adult ticks were collected from main body regions of cattle which were kept under extensive management system and then transported to the parasitology laboratory of College of veterinary medicine, Haramaya University for identification. Out of the total 384 cattle examined, $229(59.6 \%)$ were found to be infested by one or more tick species. In this study, 1201 adult ticks were collected and identified to genera level. Four tick genera (Amblyomma, Rhipicephalus, Boophilus and Hyalomma) were identified. The highest tick prevalence recorded was Amblyoma with a prevalence of $38.5(\mathrm{n}=462)$ followed by Rhipicephalus recording 29.9 $(\mathrm{n}=356)$ prevalence. The prevalence of tick infestation was found to be statistically significant $(\mathrm{P}=0.032)$ among the age groups, with highest prevalence in adult than young animals. In female animals higher tick prevalence was obtained than male animals in the study area with no statistical significant difference. Special attention should be given to the control and prevention of ticks in the study area.
\end{abstract}

Keywords: Harari, Ticks, Prevalence

\section{Introduction}

Ethiopia have a huge number of live stock population having an estimated number of 53 million cattle, 55.51 million small ruminants, more than 1 million camels, 4.5 million equines and 40 million chickens respectively [5], which plays a significant role in the socio-economic life of the people. It is well known that livestock products and byproducts in the form of meat, milk, cheese, and butter supply the needed animal protein that contribute to the improvement of the nutritional status of the people. The animals also play an important role in providing export commodities, such as meat, live animals, hides and skins to earn foreign exchange to the country. Besides, farmyard manure and wool are also important products of cattle and small ruminants [1].

In Ethiopia ticks are directly or indirectly involved in causing considerable financial losses to livestock industry accounts for $75 \%$ of the animal exports [24]. It is estimated about 1 million birr loss annually through rejection and down-grading of hides and skins in the country [9]. The introduction of exotic breeds with high productivity to different administrative regions in Ethiopia revealed that ticks are important vectors of several fatal diseases of animals. Ticks are common in all agro ecological zones of the country. In contrast to this huge economic loss caused by ticks, some of the owners neglect ticks as animal health problem, most of them have little knowledge about effect of tick on their animals and few know diseases transmitted to domestic animals by ticks [1].

In Ethiopia tick born disease contribute to the most important animal disease problem. In Ethiopia ticks occupy the first rank amongst external parasites and the economic losses in cured when they infest live stock particularly cattle's. Ixodid ticks are important in veterinary medicine, primarily as a vector of various pathogenic microorganisms such as protozoan's ricketisia including babesiosis, anaplasmosis, 
cowdrosis and viruses. In addition they may also cause direct damage such as reduction of quality of hides reduction in live weight gain, anemia, toxemia and paralysis [8].

Several tick species are widely distributed in Ethiopia the major tick genera are Amblyoma, Boophilus, Haemophysalis, Hyaloma and Rhipicephalus. Over 60 tick species are known to exist in the country. The most economically important and widely speeded ticks are Amblyoma variegatum and Boophilus decloratus. The distribution of $A$. variegatum is similar to that of $B$. decloratus and together these two species constitute more than half of the total collection [19]; [17]. $A$. variegatum and $R$. pulchelus are confined to semiarid areas [18] and low land tick densities are usually greater than those in highlands. Amblyoma, Boophilus and Ripicephalus ticks are mainly parasites of livestock. Tick population levels in local cattle are generally low for most of the year. But the number increase during the rainy season [19]. Accaricide application is still the main tick control method. Certain cultural practices such as hand picking of ticks burning with hot iron and plant preparations are widely used by cattle owners in the rural areas. Ticks on local cattle are treated whenever the farmers bring their animal to the veterinary clinics either for tick control or due to other problems [20].

Frequent and seasonal domestic ruminants disease case have been presented to the veterinary clinics and reported from many farmers around the study area with a suspect of different tick borne diseases particularly in the beginning of the raining season when tick infestation of the animals get rise. Production losses particularly milk and body weight reductions have been also becoming the main problems of the area. In the study area little attention have been given to ticks in which they are becoming major health, productivity and breeding concerns of cattle particularly in small holder's farmers. Consequently, very limited information exists or/and none at all. Accordingly, detailed investigation on Ixodid tick incidence in order to organize efforts to at least minimize losses due to tick and tick-borne diseases was needed.

Objective of the study

This study was planned to:

1. Estimate the prevalence of Ixodid ticks in cattle from three selected sites of Harari region, eastern Ethiopia.

2. Identify the major adult tick species present on the animals in the area.

Significance of the study

This research would have a number of benefits and beneficiaries first; the agricultural and rural development office workers, concerned professionals, the development agents and peoples at the area would understand the severity of the problem and so help to manage tick infested animals. This study would be used as a data to further study the implications of tick infestation in cattle at the study area.

\section{Material and Methods}

\subsection{Study Area Description}

Harari region is located $526 \mathrm{~km}$ far from Addis Ababa in
East direction at a latitude of $8^{\circ} 50^{\prime}-9^{\circ} 15^{\prime} \mathrm{N}$ and longitude of $9^{\circ} 36^{\prime} \mathrm{N} 41^{\circ} 52^{\prime}$ East and situated at an altitude of 1850 masl The annual rainfall of the area is between 834 and $1300 \mathrm{~mm}$. This area experiences a binominal rainfall pattern with a long rainy season from June to September and short rainy season from March to April while the annual temperature ranges from $21-26^{\circ} \mathrm{C}$. In Harari region there are an estimated amount of around 44,199 cattle, 4130 sheep, 36320 goats and 1400 camel.

\subsection{Study Animals}

The study was conducted on local breed of cattle found in the area and conducted on the total of 384 cattle. The animals were sampled by using randomly sampling method technique from the study site for tick collection and identification from different body region of the animal.

\subsection{Study Design}

A cross-sectional study was conducted from December 2015 to April 2016 to study the prevalence of ticks and identify major types of tick species in three selected sites of the region namely; Sofi, Dire Teyara and Erer with a total number of 384 cattle. All the animals investigated were categorized in to age, breed and sex groups according to Nicholson and Butterworth (1986). The samples were taken by random sampling method. The age determination was made according to Aiello and Mays (1998) when calves, less than 6 months old were considered as "young animals" whereas animals more than 6 months old were included in the "adult" group.

\subsection{Tick Collection and Identification Methods}

Each sampled animal was subjected to a thorough physical and clinical examination where history, acaricide treatment, any concurrent disease and signs including pain, lameness, and loss of appetite was recorded. Ticks were collected from half body of animals using forceps at main body sites namely: head, dewlap, brisket, belly and back, udder or scrotum, anogenital, leg and tail during the study period. Adult ticks collected from each of main body sites were maintained in universal bottles separately and then transported to the parasitology laboratory of College of veterinary medicine, Haramaya University for identification. Date of collections, place of collections, body sites of collection, and breed of host were recorded. The collected tick was put in to universal bottles containing $70 \%$ ethanol. Identification and recording of tick samples were taken place within few hours of collection. Ticks were identified using stereomicroscope following the standard identification procedures described by [23].

\subsection{Data Entry and Statistical Analysis}

All the data collected in the study period were entered and managed in Microsoft excel ware subsequently analysed using computer soft ware of SPSS version 16. The overall prevalence of tick infestation was determined by dividing the 
number of positive sample by total sample size and was expressed as percentage. Chi-square test was used to assess statistically significant association in tick infestation between age, breed and sex group.

\section{Result}

\subsection{Overall Prevalence}

Out of the 384 animals examined, ticks were found on 229 animals giving an overall prevalence of $59.6 \%$ (Table 1).

Table 1. Prevalence of tick in selected areas of Harari region.

\begin{tabular}{lll}
\hline No. of animal examined & No. of positive animals & No. of negative animals \\
\hline 384 & 229 & 155 \\
\hline
\end{tabular}

\subsection{Prevalence of Tick Infestation in Cattle by Kebele's}

The overall prevalence of tick infestation in the present study was 59.6\%. Slightly higher prevalence was recorded in Sofikebele $(62.8 \%)$ followed by Dire Teyara with a prevalence of $59.7 \%(n=71 / 119)$ and comparatively lower prevalence was recorded in Ererkebele (55\%). There was no significant different between occurrences of infestation in study kebeles (Table 2).

Table 2. Prevalence of tick infestation in cattle by kebeles of the study areas.

\begin{tabular}{lllll}
\hline Kebele & No of animals examined & No of positive & Prevalence & p-value \\
\hline Sofi & 156 & 98 & $62.8 \%$ & 0.447 \\
Dire Teyara & 119 & 71 & $59.7 \%$ & 1.611 \\
Erer & 109 & 60 & $55 \%$ \\
Total & 384 & 229 & $59.6 \%$ \\
\hline
\end{tabular}

\subsection{Prevalence of Tick Based on Genera Level}

Identification of tick genera and their abundance was carried and of the total 1201 Ixodid ticks collected from different body parts (base of the tail, udder and scrotum) of 384 cattle. Four different genera were indentified. The tick genera's identified were Rhipicephalus (29.9\%), Boophilus (20.8\%), Ambylomma (38.5\%), and Hyalomma (10.8\% (Table 3).

Table 3. Distribution of Ixodida tick genera in selected areas of Harari region.

\begin{tabular}{llll}
\hline Name of tick genera & Total collected ticks samples & No. of positive tick genera & Prevalence (\%) \\
\hline Rhipicephalus & 1201 & 359 & 29.9 \\
Boophilus & 1201 & 250 & 20.8 \\
Ambylomma & 1201 & 462 & 38.5 \\
Hyalomma & 1201 & 130 & 10.8 \\
Total & & 1201 & 100 \\
\hline
\end{tabular}

From the tick genera identified in the study area, Ambylomma was the abundant (38.5\%) followed by Rhipicephalus (29.9\%). From the tick genera identified Hyalomma was the least abundant (10.8\%).

\subsection{Prevalence of Tick Infestation in Cattle by Sex and Age}

The prevalence of tick infestation in the present study revealed that the occurrence of tick in both sex of animals were not significantly different ( $\mathrm{p}>0.05)$ (Table 3$)$. According to the present study findings, there was statistically significant association between age of the animals and level of tick infestation $(\mathrm{P}=0.032)$ (Table 4$)$.

Table 4. Prevalence of tick infestation in cattle of the study area by sex and age.

\begin{tabular}{lllll}
\hline Factors & No of animals examined & No of positive Animals & Prevalence & $\chi^{2}$ \\
\hline Sex & & & & 0.18 \\
Male & 157 & 93 & $59 \%$ & 0.894 \\
Female & 227 & 136 & $59.9 \%$ & \\
Total & 384 & 229 & $59.6 \%$ & \\
Age & & & & \\
Young & 83 & 41 & $49.4 \%$ & 0.03 \\
Adult & 301 & 188 & $62.5 \%$ & \\
Total & 384 & 229 & $59.6 \%$ & \\
\hline
\end{tabular}

\section{Discussion}

This study revealed that ixodid ticks are widespread and most significant external parasites of cattle in the area with an overall $59.6 \%$ prevalence that were found to be infested with at least a single tick or more. This finding is relatively in line with previous finding reported by [4] who found $62.04 \%$ in Wolayita Zone, Ethiopia. [13] reported 97.8\% prevalence which is higher than the current work. The result is in line 
with a finding in Humbo by [16] and Wolaita Soddo by [4] in which they found overall prevalence of $61.98 \%$ and $65.5 \%$ respectively. The highest prevalence of the tick $(80 \%)$ was reported by [22] in Asela.

Amblyomma is the first widely spread genera with $38.5 \%$ prevalence in the study area. The genera are one of the widely distributed cattle tick in Ethiopia [7]. Amblyomma was also frequently encountered by different researchers and it is the most abundant tick's genera in Bahir Dar [12]. It is a great economic importance because it is an efficient vector of heart water, Nairobi sheep disease and Q-fever [15]. Some species of Amblyomma often leads to ulcer formation because they have long mouth parts with which they can inflict a deep painful bite which may become secondary infection and also has a direct causal relationship with sever clinical dermatophylosis. Other species of Amblyomma (A. lepidium) was reported by several workers [18]; [19]; [12] in southwestern parts of Ethiopia including Gambella and Western Zones of Oromia showing different prevalence. The tick is irregularly dispersed through most parts of the country. It occurs in arid and semi-arid areas and also in woodland, bush land as well as grassland with either trees or bushes present [10].

Rhipicephalus is the second abundant tick species (29.9\%) in this study area. This finding was a bit higher than the works conducted by [21] at Ghibe Tullary in central Ethiopia who reported $21.19 \%$ of prevalence. This tick shows an apparent preference for any particular altitude, rainfall or season [18]. It is a possible vector of Babesia, Rickettisa and Theleria [11]. The occurrence of these genera with lower prevalence was reported by other authors [7]; [19]; [20]. Boophillus was found to be the third abundant tick species in the area $(20.8 \%)$. This result comparatively agrees with the finding reported by [13] at Bedelle district, South Western Ethiopia having $23.7 \%$ prevalence. This is not in agreement with [20] who described that Boophillus is the commonest and most wide spread tick in Ethiopia, collected in all administrative regions except in the Afar region. This present finding is also not in line with [22] in Asela, who reported the highest prevalence of Boophillus (80\%). The current result disagreed with the findings of [3] at Metekel Ranch, Ethiopia showing prevalence of $5.7 \%$. This difference may be due to the geographical location and altitude factors. The one host ticks of the genus Boophilus that parasitize ruminants represent a hindrance to livestock faming in tropical and sub-tropical countries. They transmit the causative agents to anaplasmosis ("gall sickness") and babesiosis ('red water') in cattle [23]. The least prevalent was seen in Haylomma genera and it accounts $10.8 \%$ of the total ticks collected in the study area. This tick species causes abscesses and sloughing of the host skin and it may also be associated with foot-rot of sheep. It is found in sub-Saharan Africa and rift valley and as far as South Africa. This tick species is also commonly found throughout the drier Ethiopia faunal region [15], and highly abundant in low land parts of the country as reported by [12]. [3] at Metekel Ranch, Ethiopia reported Haylomma prevalence of $5.7 \%$. The mean burden was significantly associated with age of the animals $(P=0.032)$ in that adult animals had significantly higher tick loads than young animals. This is probably associated with decreases in immunity as the animals get older. In this study the prevalence of tick infestation between different Kebeles was $62.8 \%, 59.7 \%$, and 55\% in Sofi, Dire Teyara and Erer Kebeles respectively and the difference was not significant $(\mathrm{P}>0.05)$. This is could be due to the same Agro-ecological conditions.

\section{Conclusion and Recommendations}

According to the present result, 59.6\% overall prevalence of tick was observed in the study area. In this study Amplyommawas found to be the most abundant tick genera $(38.9 \%)$ and the least was Hyalomma (10.8\%). Four tick species genera were identified in the study area namely; Ambylomma, Rhipicephalus, Boophilus, and Hyalomma. The prevalence on sex bases illustrated that it is higher for females than males. The prevalence rate based on age of the animal also showed that adult animals are more affected than young animals. The result indicates higher prevalence of ticks in the area. This may result in huge loss in hide and skin loss, body weight loss and other economic important factors. Therefore, based on the above conclusion the following recommendations are forwarded:

1. Effective tick control program should be formulated and implemented based on the distribution pattern of ticks and factors responsible for their destruction.

2. Appropriate pasture management in communal grazing area should have to be given a consideration.

\section{Competing Interests}

No competing interests existing.

\section{Author Contributions}

MM: Conception of the research idea, drafting the manuscript. TD: designing Data collection, interpretation of the results and AW: Data analysis and edition. The author read and approved the final manuscript.

\section{References}

[1] Abunna, F., Kasasa, D., Shelima, B., Megersa, B., Regassa, A. and Amenu, K. (2009): Survey of tick infestation in small ruminants of Miesso district, West Harergie, Oromia Region, Ethiopia, Trop Anim Health Prod. 41: 969-972.

[2] Aiello, S. E. and Mays, A. (1998): The Merck Veterinary Manual, 8th Ed, Pp: 131- 140.

[3] Alekaw, S. (1998): Distribution of ticks and tick-borne diseases at Metekel Ranch. Ethiop. Vet. J. 4 (1): 30.

[4] Ammanuel, W. and Abdu, M. (2014): Prevalence of Ixodid Ticks on Bovine in Soddo Zuria Districts, Wolaita Zone, Ethiopia. Acta Parasitologica Globalis 5 (3): 188-197. 
[5] Central Statistics Authority (CSA):(2014): Agricultural sample survey 2010-2012 Report on livestock and livestock characteristics vol. II, Statistical Bulletin No. 446, Addis Ababa, Ethiopia.

[6] De-Castro, J. J and New Son, R. M. (1993): Host resistance in cattle tick control. Parasitology today (9): 13-17.

[7] De-Castro, J. J. (1994): A Survey of the Tick Species in Western Ethiopia, Technical Report, Food and Agricultural Organization of the United Nations (FAO), Rome, Italy.

[8] Feseha, G. (1983): Notes on tick species and tick born disease of domestic animals in Ethiopia, DVM thesis AAU Debre-zeit, Ethiopia. Pp: 12-15.

[9] Hagos, A., Yacob, H. and Mulugeta, Y. (2013): Impact of sheep and goats ectoparasites on the tanning industry in Tigray Region, Ethiopia Ethiop. Vet. J., 17 (2); 63-76.

[10] Horak, I. G., Gallivan, G. J. and Spickett, A. M. (2011): The dynamics of questing ticks collected for 164 consecutive months off the vegetation of two landscape zones in the Kruger National Park (1988-2002).

[11] Kettle, D. S. (1995): Medical and Veterinary Entomology. $2^{\text {nd }}$ Ed. UK: CAB International. Pp: 420-460.

[12] Mesele, A. (1989): Bovine tick survey in Bahir Dar Awraja, DVM thesis, Faculty of Veterinary Medicine, Addis Ababa University, Debrezeit Ethiopia. Pp: 13-21.

[13] Mesele, A., Tirazu, M., Rahmeto, A., Kassaye, A. and Jemere, B. (2010): Survey of ixodid ticks in domestic ruminants in Bedelle district, Southwestern Ethiopia. Trop. Anim. Health Prod. 42: 1677-1683.

[14] Nicholson, M. and Butterworth, T. (1986): A guide to body condition score in zebu cattle international livestock center for Africa, Addis Ababa, Ethiopia.

[15] Okello-Onen J, Hassan SM, Seaman, S. (1999): Taxonomy of African tick, an identification manual, International center for insect physiology and ecology press, Nairobi, Kenya 1: 124.
[16] Pawlos, W. and Derese, D. (2013): Study on prevalence and identification of ticks in Humbo district, Southern Nations, Nationalities, and People's Region (SNNPR), Ethiopia. Journal of Veterinary Medicine and Animal Health Vol. 5 (3), 73-80.

[17] Pegram, P. G., R. J. Tatchell, J. J. De Castro, M. J. Chizyuka, P. G. Mc Cosker, M. C. Moran and G. Nigarura, (2004): Tick control: New concepts.

[18] Pegram, R. G. Hoogstral, and Wassef, H. Y. (1981): Ticks (Acari: Ixodiade) of Ethiopia. Distribution, ecology and relation of species infesting livestock, Bull. Entomol. Res. 71: 335-359.

[19] Sileshi, M. (1995): Ticks, tick borne pathogens at the hostvector interface, A global perspective.

[20] Sileshi, M, Pegram, R. G., Solomon, G., Abebe, M., Yilma, J. and Sileshi, Z. (2007): A synthesis of review of Ixodids (Acari: Ixodiade) and Argas (Acari: Argasidae) ticks in Ethiopia and their possible role in diseases transmission. Ethiop. Vet. J. 2: $1-22$.

[21] Solomon, G., Sileshi, M., Nigist, M., Thomas, C., Getachew, T., Abebe, M., Genet, B., Demeke, S. and Ejigu, Z. (2007): Distribution and seasonal variation of ticks on cattle at Ghibe Tollay in central Ethiopia, Ethiop. Vet. J. 11: 121-139.

[22] Tamiru, T. (2008): Survey of Bovine tick species in and around Asela Town, DVM Thesis, school of Veterinary Medicine, Jimma University, Jimma, Ethiopia. Pp: 18-22.

[23] Walker, A. A. Bouatour, A., Camicas, J. L. Estadapena, A. A, Harok, I. G., Hatif, A. A., Pegram, R. G. and Preton, P. M. (2003): Ticks of domestic animals in Africa: A guide to identification species, Pp. 67-80.

[24] Zeleke, M. and Bekele, T. (2004): Species of ticks on camels and their seasonal dynamics in Eastern Ethiopia. Tropical Animal Health and Production, 36; 225-231. 